\title{
Phase Change Materials to Meet Domestic Space Heating Demand in the UK - A Numerical Study
}

\author{
Jose Pereira da Cunha, Philip C. Eames \\ Centre for Renewable Energy Systems Technology (CREST); Loughborough University \\ Loughborough (Leicestershire) LE11 3TU, United Kingdom \\ j.pereira-da-cunha@lboro.ac.uk; philip.c.eames@lboro.ac.uk
}

\begin{abstract}
This paper presents a performance evaluation of two domestic space heating systems that use air source heat pumps (ASHP) to replace conventional boilers with air source heat pumps (ASHP). The storage system consisted of encapsulated PCM spheres in a packed bed with twice the storage capacity over the temperature range of 40 and $65^{\circ} \mathrm{C}$ achievable with hot water. The simulations predicted a potential $\mathrm{CO}_{2}$ reduction of $23 \%$ for the detached dwelling and $20 \%$ for the semi-detached dwelling, operating the heat pumps in economy 10 electricity i.e a low tariff at times between 00.00-05.00 and 13.00-16.00; with current grid emission values by successfully offsetting the electrical load to meet the heat demand.
\end{abstract}

Keywords: Phase change materials; thermal energy storage; domestic space heating; air source heat pumps, finite volume numerical model

\section{Introduction}

Nearly a fifth of the UK's final energy consumption in 2014 was used for conventional heating applications in the domestic sector using naturals gas and petroleum products [2]. In order to decarbonize the sector, heat pumps are an option that is being considered; however, their use should be restrained to off peak times to prevent an increase in the peak electrical grid demand [3].

Error! Reference source not found. presents the composition of the generation by source supplied to the UK national grid on the $15^{\text {th }}$ January 2015. The $\mathrm{CO}_{2}$ emissions associated with this profile were calculated based on the emission coefficients obtained by Hawkes et al. [4]Error! Reference source not found.. To effectively decarbonize the sector, heat pump $\mathrm{CO}_{2}$ emissions should be less than that of the conventional gas burning domestic heating systems (around 204 $\mathrm{gCO}_{2} / \mathrm{kWh}_{\text {th }}$ [2], [4]); and their usage should the restricted to off peak times to minimise both carbon intensity and peak load. To meet these requirements, heat pumps are usually operated using the economy 10 or economy 7 tariffs [1], with hot water buffer tanks used to offset the electrical load and meet the heat demand required.

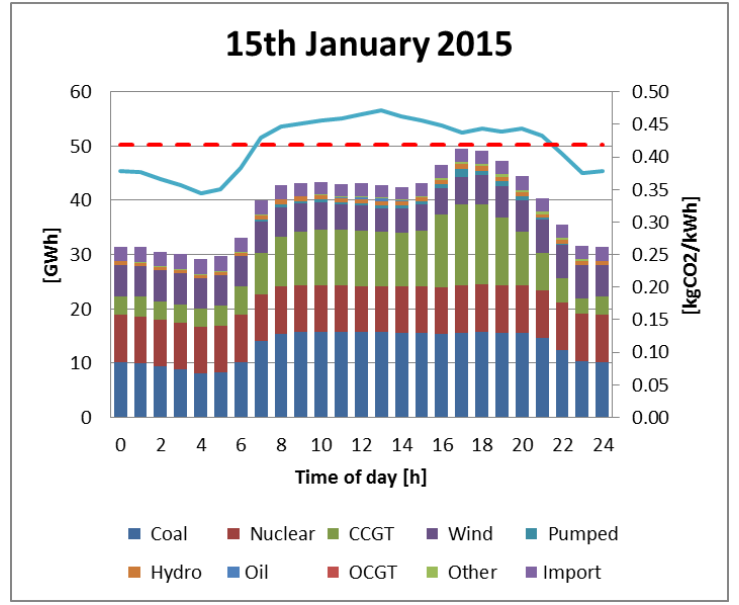

Fig. 1: Hourly variation of $\mathrm{CO} 2$ emissions associated with the electricity supplied by the UK national grid [4] - sample date: $15 / 01 / 2015$. 
Hot water buffer tanks have constant heat capacity in the working temperature range for conventional space heating $\left(50\right.$ to $60^{\circ} \mathrm{C}$ ), hence requiring an excess volume to maintain $8 \mathrm{~h}$ space heating; leading to an extra demand of heat to charge it to the required temperature. Encapsulated phase change materials (PCMs) with a phase transition temperature between 50 and $60{ }^{\circ} \mathrm{C}$ can effectively increase the storage capacity of common hot water cylinders in a narrower temperature range, hence reducing the required buffer tank volume, allowing more heat to be stored for a given volume. Known organic PCMs melting in this temperature range are the Paraffin waxes (RT54HC [5]) and a mixture of stearic acid and palmitic acid [6]. Other PCM candidates are the salt hydrates, but their high subcooling usually discards them to work in a narrow temperature range. A eutectic mixture of two salt hydrates with low subcooling was successfully tested using differential scanning calorimetry and temperature driven heat capacity curves (Fig. 2) were obtained and compared with the organic PCM candidates. Table 1 presents a comparison of the three candidates, and the salt hydrate eutectic mixture is 3 times more energy dense than water, with a working temperature range from 40 to $65^{\circ} \mathrm{C}$.

Table 1: Comparison of candidate PCMs for space heating applications.

\begin{tabular}{|c|c|c|c|c|c|c|c|}
\hline \multirow{2}{*}{ PCM candidates } & $T_{\text {min }}$ & $\mathbf{T}_{\max }$ & \multirow{2}{*}{\begin{tabular}{|l}
$\mathbf{H}_{\text {stored }}$ \\
$\mathbf{k W h} / \mathbf{m}^{3}$
\end{tabular}} & \multirow{2}{*}{$\mathbf{H} / \mathbf{H}_{\mathrm{H} 2 \mathrm{O}}$} & $\lambda$ & \multicolumn{2}{|l|}{ Price } \\
\hline & ${ }^{\circ} \mathbf{C}$ & & & & $\mathbf{W} / \mathbf{m} . \mathbf{K}$ & $£ / \mathbf{m}^{3}$ & $\mathfrak{f} / \mathbf{k W h}$ \\
\hline $\begin{array}{|ll|}\mathrm{MgCl}_{2} \cdot\left(\mathrm{H}_{2} \mathrm{O}\right)_{6} & + \\
\mathrm{Mg}\left(\mathrm{NO}_{3}\right)_{2} \cdot\left(\mathrm{H}_{2} \mathrm{O}\right)_{6} & \\
(\mathrm{SH}-\mathrm{SH}) & \end{array}$ & \multirow{3}{*}{40} & \multirow{3}{*}{65} & 83 & 2.9 & 0.600 & 99 & 1.19 \\
\hline $\begin{array}{l}\text { stearic acid + palmitic } \\
\text { acid (SA-SPA) }\end{array}$ & & & 61 & 2.14 & 0.260 & 351 & 5.72 \\
\hline RT 54HC & & & 55 & 1.92 & 0.200 & 421 & 7.63 \\
\hline
\end{tabular}

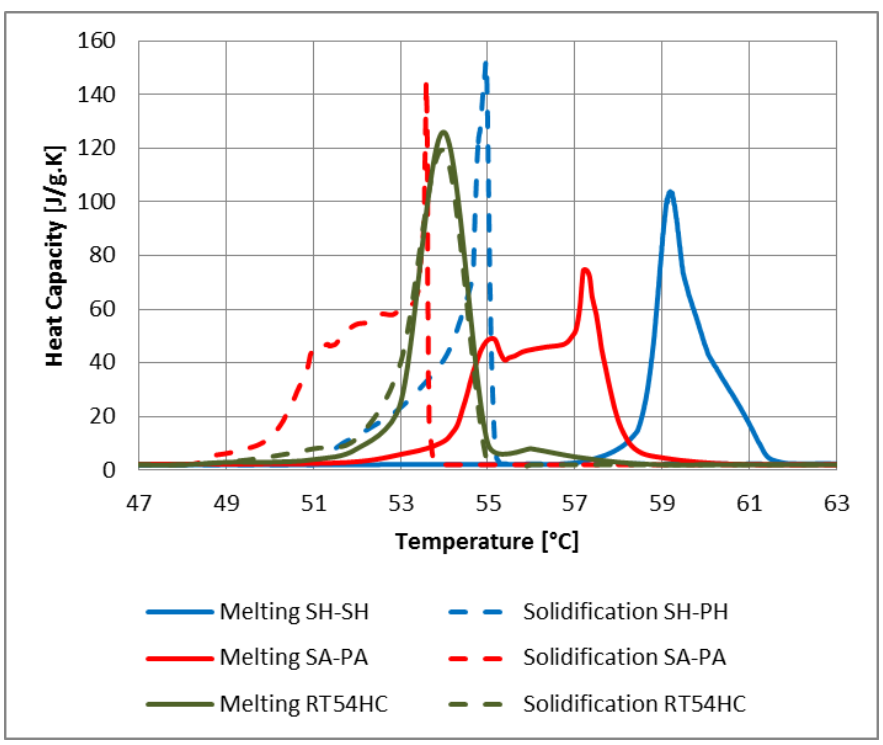

Fig. 2: Heat capacity curves comparing the three selected PCMs.

\section{Numerical Model}

A finite volume 2D numerical algorithm was developed in Matlab to model a packed bed latent heat energy storage system, with macro-encapsulated PCM spheres and only thermal diffusion considered in the PCM. The container was considered to be made of a number of horizontal layers each having a set number of spheres with thermal stratification illustrated in Fig. 3. Each layer was represented by a single node. To charge and discharge, it was considered a flow rate passing through the spheres, exchanging heat through convection with the HTF, and the container walls were considered to be adiabatic. 

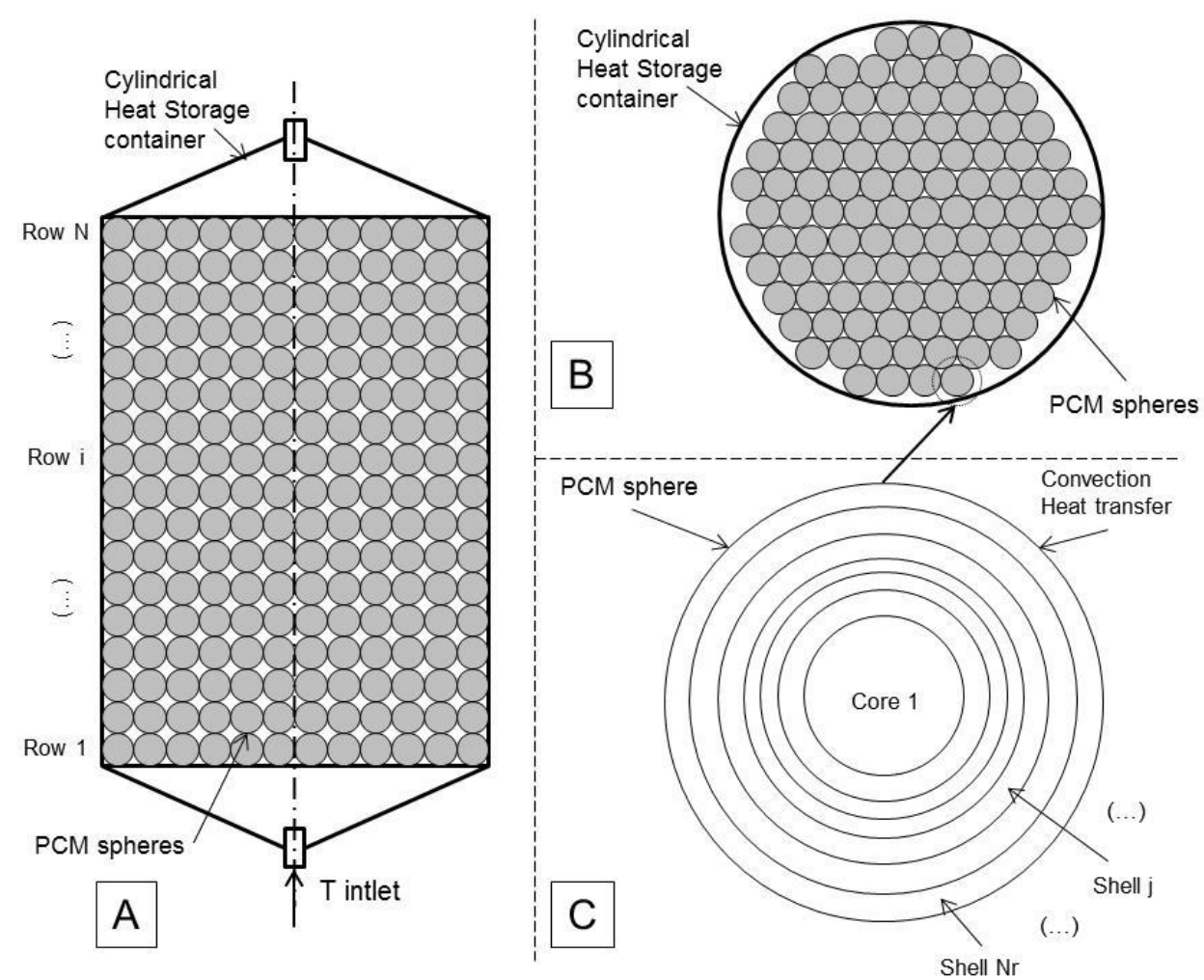

Fig. 3: Schematic representation of the packed bed model in longitudinal cross section (A), transversal cross section with possible spheres arrangement (B) and detailed view of the division process within the sphere (C).

The numerical model assumed the thermal conductivity of the PCM was constant and isotropic, with no volume change during phase change. To account for change in heat capacity of the PCM during phase change, temperature driven heat capacity curves were obtained for each PCM using differential scanning calorimetry analysis at a temperature ramp rate of $\left(1^{\circ} \mathrm{C} / \mathrm{min}\right)$ were used.

The heat transfer flow (HTF) Reynolds number was calculated using equation 1, accounting for the HTF void fraction within the container $(\varphi)$, and considering the flow length to be half of a sphere's cross section perimeter. The convection heat transfer coefficient was determined using the method detailed in [7], where the average Nusselt Number, expressed in eq. 2, is the product of the form factor (fa), calculated according to eq. 3 considering a packed bed with spheres of the same size; by the Nusselt number for a packed bed, calculated according to Gnielinski (eq. 4 and eq. 5), provided from [8].

\begin{tabular}{|l|l|}
\hline$R e_{\Phi}=\frac{2 \times \rho_{h t f} \times Q \times d_{\text {sphere }}}{\mu_{h t f} \times D_{\text {cont }}^{2} \times \Phi_{\text {htf }}}$ & $(1)$ \\
\hline$N u=f_{a} \times\left(2+\sqrt{N u_{\text {lam }}^{2}+N u_{\text {turb }}^{2}}\right)$ & $(2)$ \\
\hline$f_{a}=1+1.5 \times(1-\Phi)$ & $(3)$ \\
\hline$N u_{\text {lam }}=0.664 \times \sqrt{\operatorname{Re}_{\Phi}} \sqrt[3]{P r}$ & $(4)$ \\
\hline$N u_{\text {turb }}=\frac{0.037 \times R e_{\Phi}^{0.8} \times P r}{1+2.443 \times \operatorname{Re}_{\Phi}^{-0.1}\left(\operatorname{Pr}^{\frac{2}{3}}-1\right)}$ & $(5)$ \\
\hline
\end{tabular}

\subsection{Model Verification}

Tanvir et al. [9] studied a packed bed containing 770 capsules of sodium nitrate as PCM charged and discharged with air $20{ }^{\circ} \mathrm{C}$ above and below the PCM melting point. Fig. 5 presents the rig configuration and sodium nitrate heat capacity curves within the working temperature range. The system stored a total of $2 \mathrm{kWh}_{\text {th }}$ between 286 and $326^{\circ} \mathrm{C}$, with air heaters maintaining the charging and discharging temperatures at the required levels. 
Table 2 presents the system's properties.

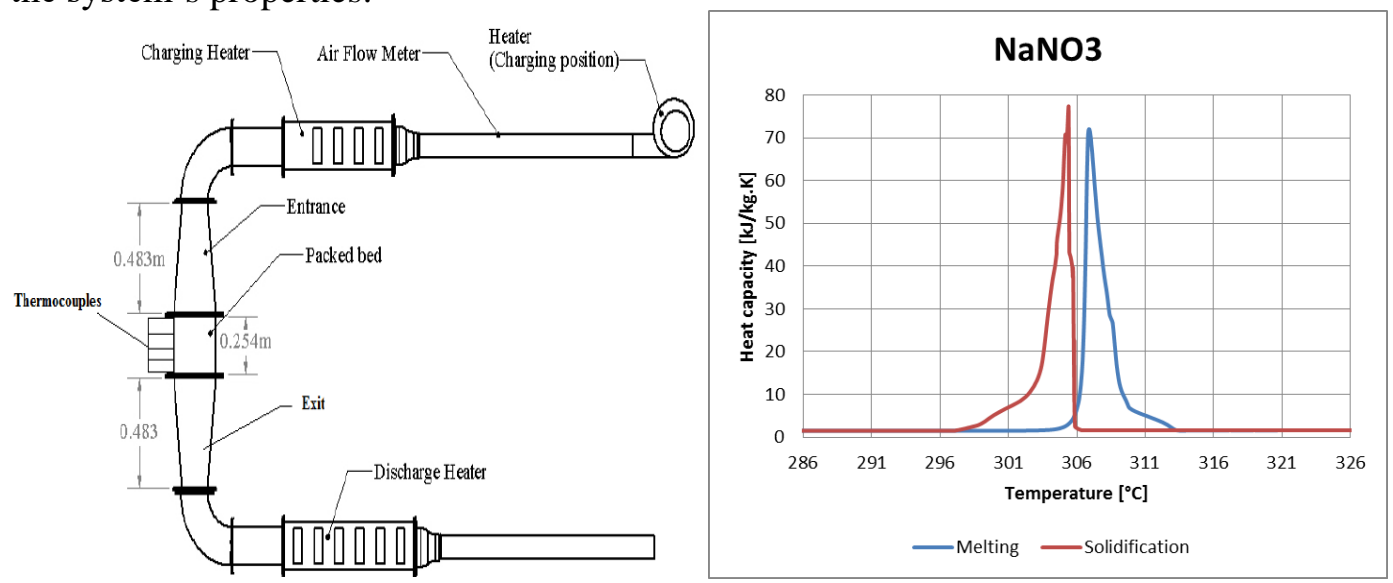

Fig. 4: Schematic representation of the experimental rig used by Tanvir et al.[9] and heat capacity curves obtained in DSC analysis.

Table 2: Store dimansions and heat transfer fluid flow properties for the experiments made by Tanvir et al. [9].

\begin{tabular}{|l|l|}
\hline & \\
Bed height $[\mathrm{mm}]$ & 254 \\
Bed Diameter [mm] & 254 \\
Total Volume of packed bed [L] & 12.87 \\
Bed Porosity & 0.35 \\
HTF: & \\
Flow rate $\left[\mathrm{m}^{3} / \mathrm{s}\right]$ & 0.0419 \\
Reynolds Number $(\mathrm{Re})$ & $1293-1171$ \\
Prandlt (Number) & 0.77 \\
Nusselt Number $(\mathrm{Nu})$ & $52.3-49.6$ \\
Convection HT coefficient $\left(\mathrm{h}_{\mathrm{cv}}\right)\left[\mathrm{W} / \mathrm{m}^{2} . \mathrm{K}\right]$ & $86-87$ \\
\hline
\end{tabular}

The model predictions and the experimental results are presented in Fig. 5. It is clear to see that there is a good correlation in both the air and PCM temperature profiles. The slight discrepancies in the melting process are probably due to not modelling buoyancy effects of molten PCM in the numerical model.

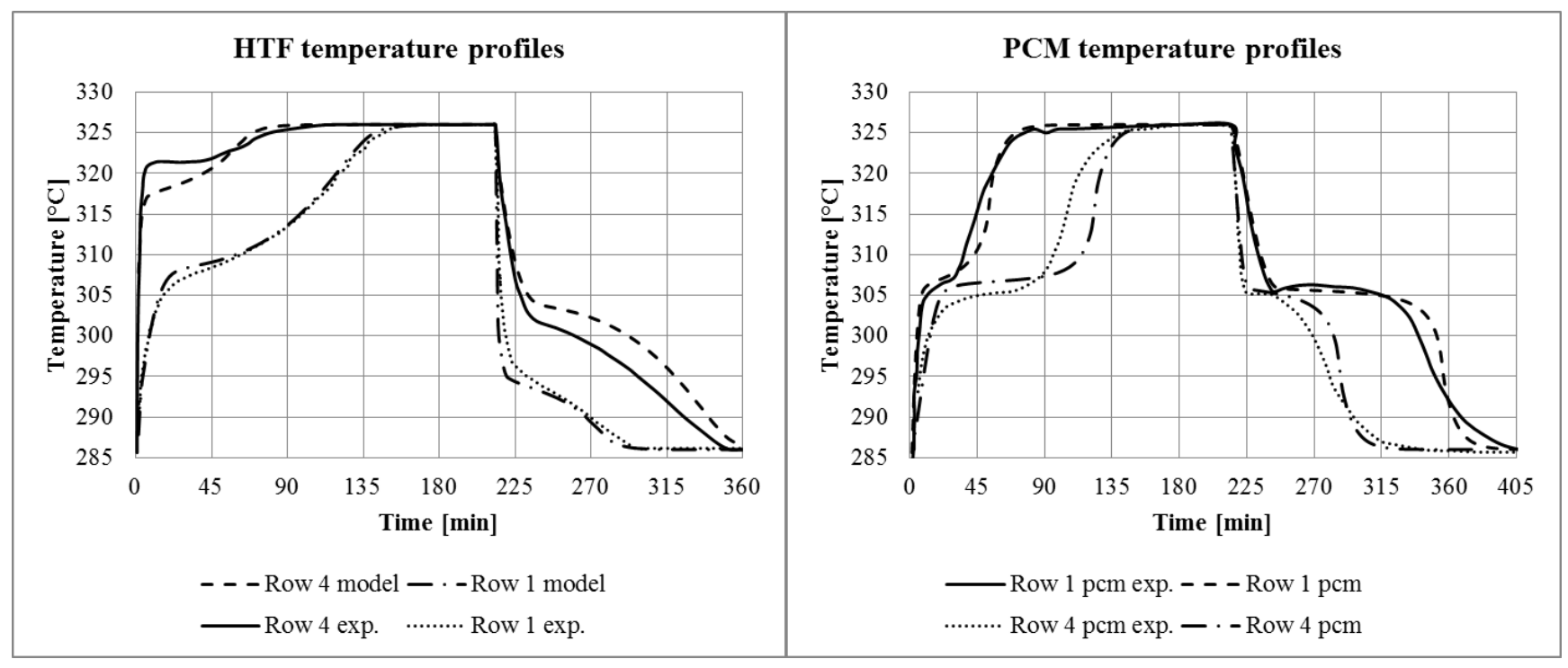


Fig. 5: Experimental and predicted inlet-outlet air temperatures and inner capsule temperatures.

\subsection{System design and integration}

The packed bed store was then integrated into a simulation of a conventional domestic central heating system, Fig. 6, charged during the off peak hours (economy 10) using a Daikin Altherma V high temperature heat pump [10]. The store was designed to provide a heat demand of $8 \mathrm{~h}$ for a typical Victorian detached and semi-detached dwelling with improved thermal performance achieved by insulation retrofit during a typical winter day. The reason of selecting these two types of dwellings was their importance, since they represent a significant part of the UK's 2015 housing market, retrieved from DECC's English housing survey [11].

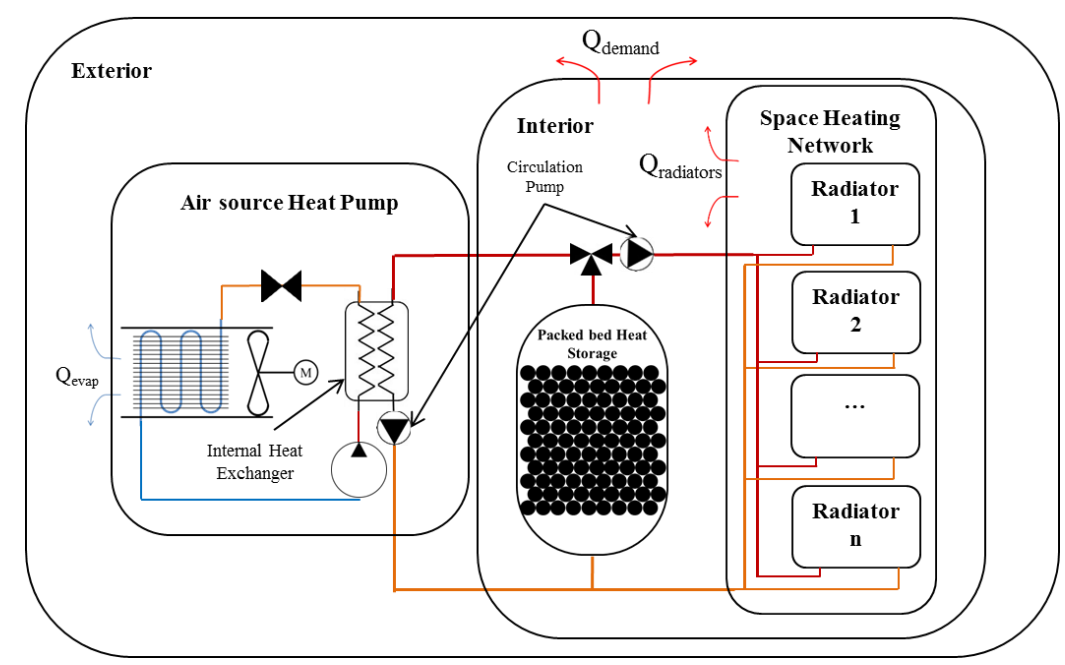

Fig. 6: Schematic representation of the packed bed store integration within a conventional domestic central heating system using an air source heat pump.

For a practical estimation of each dwellings performance, the building parameters used, displayed in Table 3, were those from an high-resolution stochastic integrated thermal-electrical domestic demand model [12], [13]. The latent heat storage system supplied the heat to the house by circulating water through the store and the supply network with a pump, Fig. 6. The temperature control system activated the pump whenever the air temperature in the building dropped below $18^{\circ} \mathrm{C}$, and deactivates when a $20^{\circ} \mathrm{C}$ is achieved. A constant $12 \mathrm{l} / \mathrm{min}$ flow rate and a parallel configuration of the heat emitters was considered for simplification purposes.

Table 3: Dwelling properties used in the numerical model.

\begin{tabular}{|l|l|l|l|}
\hline Dwelling & Detached & Semi-detached & Units \\
\hline Total & 30.02 & 20.14 & \multirow{2}{*}{$\mathrm{kh}$} \\
\hline E LHS & 10.01 & 7.15 & \\
\hline \multirow{2}{*}{ UA } & 70.45 & 51.62 & $\mathrm{~W} / \mathrm{K}$ \\
\cline { 2 - 4 } & 0.518 & 0.593 & $\mathrm{~W} / \mathrm{m}^{2} . \mathrm{K}$ \\
\hline Floor area & 136 & 87 & $\mathrm{~m}^{2}$ \\
\hline Inside volume & 332 & 239 & $\mathrm{~m}^{3}$ \\
\hline Set temp. & 19 & ${ }^{\circ} \mathrm{C}$ \\
\hline
\end{tabular}

The packed bed stores contained around 950PCM spheres for, varying the sphere's diameter, and could store twice the thermal energy compared to the same hot water volume, between 40 and $65^{\circ} \mathrm{C}$, with the increased heat capacity between 55 and $50{ }^{\circ} \mathrm{C}$, shown in Fig. 2.

Table 4 presents the most key properties of the modelled packed bed stores. For both stores, the heat transfer fluid flow is laminar, having the semi-detached house store higher convective heat transfer ratios by using smaller diameter 
spheres. To achieve good heat transfer within the store a height to diameter ratio above 2 enhances thermal stratification within the packed bed.

Table 4: Packed bed container properties used in the numerical model.

\begin{tabular}{|c|c|c|}
\hline & $\begin{array}{l}\text { Detached } \\
\text { dwelling }\end{array}$ & $\begin{array}{l}\text { Semi-detached } \\
\text { dwelling }\end{array}$ \\
\hline N spheres & 952 & 943 \\
\hline Sphere OD [mm] & 60 & 54 \\
\hline Sphere t [mm] & \multicolumn{2}{|l|}{1} \\
\hline Cont. diam.[mm] & 418 & 375 \\
\hline Cont. height [mm] & 1253 & 1125 \\
\hline Cont. vol [I] & 172 & 124 \\
\hline H/D ratio & \multicolumn{2}{|l|}{3} \\
\hline PCMvol [l] & 96 & 68 \\
\hline $\mathrm{Z}_{\mathrm{pcm}}[\%]$ & 56 & 54 \\
\hline HT ${ }_{\text {area }}\left[\mathrm{m}^{2}\right]$ & 10.65 & 8.50 \\
\hline Spec. HT ${ }_{\text {area }}\left[\mathrm{m}^{2} / \mathrm{m}^{3}\right]$ & 62 & 68 \\
\hline To water $[\mathrm{kWh} / \mathrm{kWh}]$ & 2.01 & 1.98 \\
\hline HTF flow Reynolds & $246-445$ & $266-483$ \\
\hline HTF $\mathbf{h}_{\mathrm{cv}}\left[\mathbf{W} / \mathbf{m}^{2} \cdot \mathbf{K}\right]$ & $391-453$ & $447-520$ \\
\hline Cont. capacity [kWh] & 10.01 & 7.15 \\
\hline PCM $[\mathrm{kWh}]$ & 7.94 & 5.62 \\
\hline Water + encap. [kWh] & 2.07 & 1.53 \\
\hline Emissions $\left[\mathrm{gCO}_{2} / \mathrm{kWh}\right]$ & 158 & 164 \\
\hline
\end{tabular}

\section{Results}

Fig. 7 and Fig. 8 present the predictions for a winter day using a high resolution stochastic model. In McKenna's model, there is a significant variance in the houses inside temperature around the set point temperature; this is partly due to solar gains between 10.00 and 16.00 .

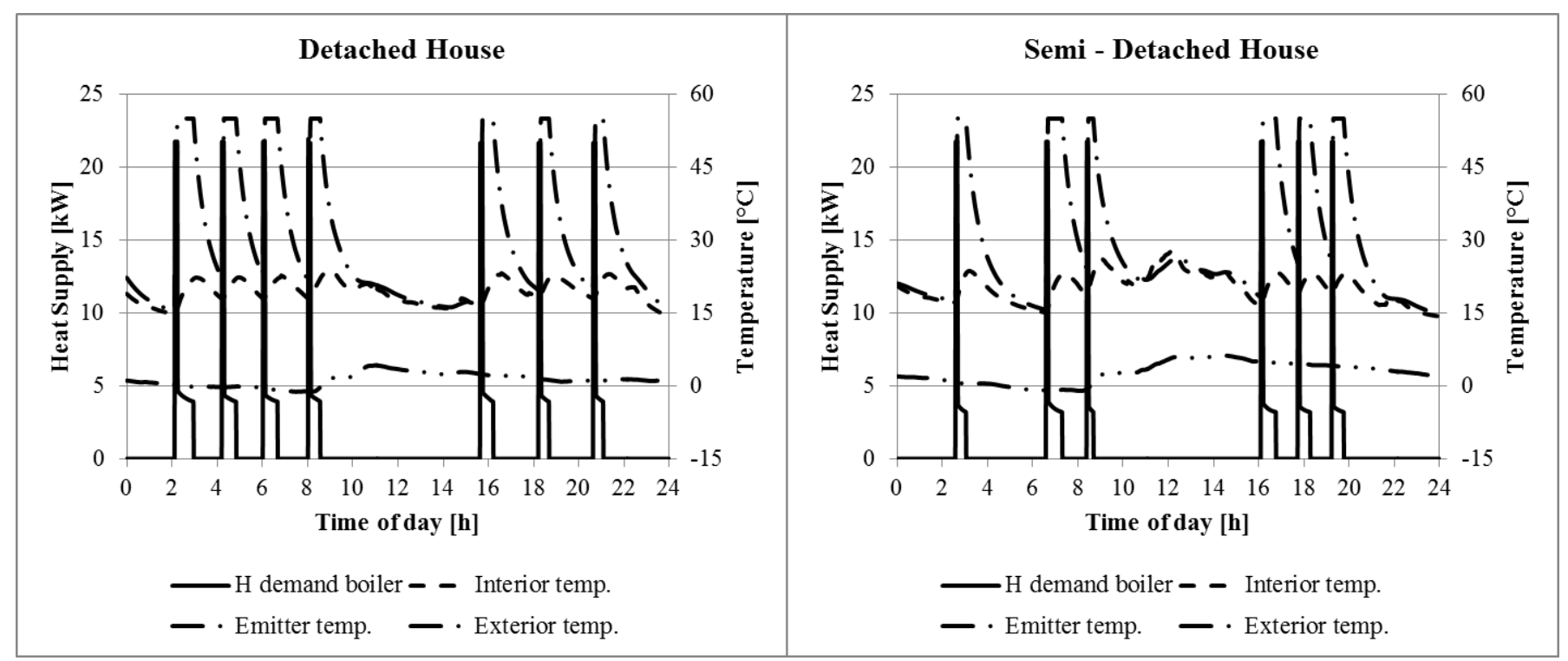

Fig. 7: Predicted results obtained by Mckenna high resolution stochastic model [13] for the detached and semi-detached dwellings. 
A simulation using a Matlab model predicts faster indoor temperature variations mainly due to a more narrow temperature control band $\left(18\right.$ to $\left.20^{\circ} \mathrm{C}\right)$, consequently leading to more variations in the heat emitter temperatures.

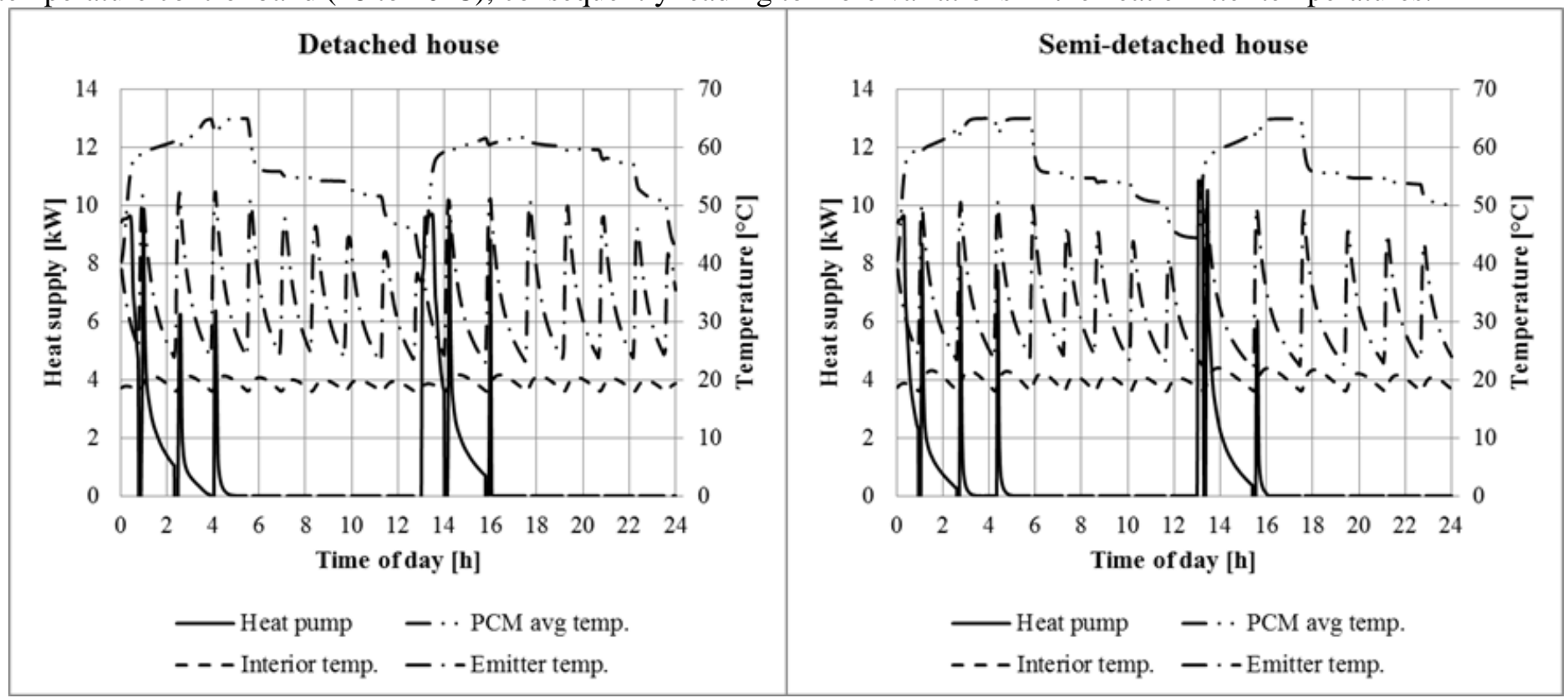

Fig. 8: Predicted results obtained in the Matlab analysis for the detached and semi-detached dwellings.

Regarding the PCM temperature, the results show that the higher thermal capacity around $55^{\circ} \mathrm{C}$ is beneficial to the system, allowing the two $8 \mathrm{~h}$ period (from 05.00 to 13.00 and from 16.00 to 24.00 ) to be fully supplied by the packed bed container, successfully offsetting the heap pump operation in economy 10 operational times. Due to the use of the same heat pump in both systems, the semi-detached dwelling had faster charging times; fully charging the system in $3 \mathrm{~h}$ and allowing the PCM to sub cool in the discharge phase. In the detached system, there was no subcooling in the $2^{\text {nd }}$ discharging period (from 16.00 to 24.00) since the PCM didn't fully melt.

The final carbon footprint reduction was $23 \%$ for the detached dwelling and $20 \%$ for the semi-detached dwelling; performance based on the current grid emission values [2], [4].

\section{Conclusion}

Phase change materials have the potential to store larger amounts of thermal energy within smaller temperature ranges compared to hot water heat storage. Due to the low thermal conductivity of many PCMs, poor rates of thermal diffusion within the PCM can seriously affect the nominal storage system charge and discharge heat rates.

Due to their geometrical flexibility, encapsulated packed bed stores seem to be a feasible option for integrating PCMs into conventional domestic space heating systems without major technical constrains. The lower PCM volume ratios achieved when compared to more compact stores such as the tube in tube systems, can reduce the increase in heat capacity that can be achieved.

The numerical model developed to evaluate the replacement of conventional boilers by heat pumps for domestic space heating applications was used to assess the potential of using phase change materials, to offset heat pump operation and a $\mathrm{CO}_{2}$ emissions reductions of $23 \%$ for detached and $20 \%$ for semi-detached dwellings were predicted using current grid emissions. Future decarbonisation of grid electricity will result in greater reductions, the need for and importance of improved thermal storage to reduce peak electrical demand and make use of variable renewables when generated will increase, PCM based thermal stores can provide significantly more storage capacity for a given volume than simple water based storage systems.

\section{Acknowledgements}

The research presented in this paper is funded by the EPSRC through Grant reference EP/K011847/1, the Interdisciplinary centre for Storage, Transformation and Upgrading of Thermal Energy (i-STUTE) and a Loughborough 
University funded $\mathrm{PhD}$ studentship. All data and materials used in this research are available for open access from Loughborough University's Data Repository or upon request.

\section{References}

[1] N. J. Kelly, P. G. Tuohy, and A. D. Hawkes, "Performance assessment of tariff-based air source heat pump load shifting in a UK detached dwelling featuring phase change-enhanced buffering," Appl. Therm. Eng., vol. 71, no. 2, pp. 809-820, 2014.

[2] K. Harris, A. Annut, and I. MacLeay, Digest of United Kingdom Energy Statistics 2015, vol. b. 2015.

[3] N. J. Hewitt, "Heat pumps and energy storage - The challenges of implementation," Appl. Energy, vol. 89, no. 1, pp. 37-44, 2012.

[4] A. D. Hawkes, "Estimating marginal CO2 emissions rates for national electricity systems," Energy Policy, vol. 38, no. 10, pp. 5977-5987, 2010.

[5] Rubitherm GmbH. (2016). Website of Rubitherm GmbH. [Online]. Available: http://www.rubitherm.eu/.

[6] G. Baran and A. Sari, "Phase change and heat transfer characteristics of a eutectic mixture of palmitic and stearic acids as PCM in a latent heat storage system," Energy Convers. Manag., vol. 44, no. 20, pp. 3227-3246, 2003.

[7] N. Wakao, S. Kaguei, and T. Funazkri, "Effect of fluid dispersion coefficients on particle-to-fluid heat transfer coefficients in packed beds," Chem. Eng. Sci., vol. 34, no. 3, pp. 325-336, 1979.

[8] W. Wagner, VDI Heat Atlas, vol. 2010. Springer Berlin Heidelberg, 2010.

[9] E. A. Tanvir, J. Dhau, D. Y. Goswami, M. M. Rahamn, and E. Stefankos, "Experimental Investigation of a Packed Bed Latent Heat Thermal Storage System with encapsulated Phase Change Material." in ASME, Montreal, Quebec, Canada, p. 6, 2014.

[10] K. J. Chua, S. K. Chou, and W. M. Yang, “Advances in heat pump systems: A review,” Appl. Energy, vol. 87, no. 12, pp. 3611-3624, 2010.

[11] DECC, "English Housing Survey," Communities, pp. 1-73, 2015.

[12] E. McKenna and M. Thomson, "High-resolution stochastic integrated thermal-electrical domestic demand model," Appl. Energy, vol. 165, pp. 445-461, 2016.

[13] M. Eoghan and T. Murray, "CREST Demand Model," 2015.

[14] F. Agyenim, N. Hewitt, P. Eames, and M. Smyth, "A review of materials, heat transfer and phase change problem formulation for latent heat thermal energy storage systems (LHTESS)," Renew. Sustain. Energy Rev., vol. 14, pp. 615$628,2010$. 